Canadian

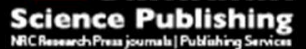

Canadian Journal of Civil Engineering Revue canadienne de génie civil

\title{
Seismic performance of embedded steel beam connection in cross-laminated timber panels for tall-wood hybrid system
}

\begin{tabular}{|r|l|}
\hline Journal: & Canadian Journal of Civil Engineering \\
\hline Manuscript ID & cjce-2016-0386.R2 \\
\hline Manuscript Type: & Article \\
\hline Date Submitted by the Author: & 09-May-2017 \\
\hline Complete List of Authors: & $\begin{array}{l}\text { Zhang, Xiaoyue; University of British Columbia } \\
\text { Azim, Riasat; University of British Columbia } \\
\text { Bhat, Pooja; University of British Columbia } \\
\text { Popovski, Marjan; FPInnovations } \\
\text { Tannert, Thomas; University of British Columbia }\end{array}$ \\
\hline $\begin{array}{r}\text { Is the invited manuscript for } \\
\text { consideration in a Special } \\
\text { Issue? : }\end{array}$ & N/A \\
\hline Keyword: & tall wood buildings, FFTT system, seismic response, mass timber systems \\
\hline & \multicolumn{2}{|c|}{} \\
\hline
\end{tabular}




\section{Seismic performance of embedded steel beam connection in cross-laminated} timber panels for tall-wood hybrid system

Abstract: Recent developments in novel engineered mass timber products and connection systems

5 have created the possibility to design and construct tall timber-based buildings. This research

6 presents the experiments conducted on the steel-wood connection as main energy dissipating part

7 of a novel steel-timber hybrid system labelled FFTT. The performance was investigated using

8 quasi-static monotonic and reversed cyclic tests. The influence of different steel beam profiles

9 (wide flange I-sections and hollow rectangular sections), and the embedment approaches (partial

10 and full embedment) was investigated. The tests results demonstrated that appropriate connection

11 layouts can lead to the desired failure mechanism while avoiding excessive crushing of the mass

12 timber panels. The research can serve as a precursor for developing design guidelines for the FFTT

13 system as an option for tall wood-hybrid building systems in seismic regions.

14 Keywords: tall wood buildings, FFTT system, seismic response, mass timber systems

15 1) Research Assistant, Wood Science, UBC Vancouver, Canada, xiaoyuezhang@alumni.ubc.ca

16 2) Research Assistant, Civil Engineering, UBC Vancouver, Canada, mrazim@alumni.ubc.ca

17 3) Research Assistant, Civil Engineering, UBC Vancouver, Canada, poojabhat@ alumni.ubc.ca

18 4) Principal Scientist, FPInnovations, Vancouver, Canada, Marjan.Popovski@fpinnovations.ca

19 5) Associate Professor, Civil Engineering, UBC Vancouver, thomas.tannert@ubc.ca 


\section{Introduction}

21 A significant number of mid-rise heavy timber structures were built across North America at the

22 beginning of the $20^{\text {th }}$ century. Fire incidents during that period were the main reason for placing

23 area and height restrictions on buildings with combustible construction materials. Such restrictions

24 remain to this day in all major national buildings codes such as the National Building Code of

25 Canada (NBCC 2010). The need to reduce the carbon footprint of buildings and recent changes in

26 legislations to increase of storey limit for light-frame wood construction from four to six stories

27 throughout Canada have revived the interest in extending the application of wood-based products

28 to mid-rise and potentially high-rise construction. Consequently, a number of new concepts of

29 wood-based structural systems (Green and Karsh 2012; Professner and Mathis 2012; SOM 2013;

30 No Name 2015) and guidelines (Karacabeyli and Lum 2014; Smith and Frangi 2014) have been

31 developed.

The availability of innovative engineered wood products (EWPs) provided engineers with

33 alternative materials that not only have desirable structural properties, but also have better

34 environmental attributes compared to other construction materials. One EWP that provides this

35 opportunity is cross-laminated timber (CLT), a product that was developed in Europe in the 1990s,

36 and is increasingly gaining popularity in residential and non-residential applications in Canada.

37 Extensive research on the seismic performance of CLT (Ceccotti et al. 2010; Fragiacomoet al.

38 2011; Pei et al. 2013; Gavric et al. 2014) confirmed the importance of the connections on the

39 overall structural behaviour, and that good seismic performance can be obtained when using ductile

40 connectors.

41 According to the objective-based design approach in the NBCC (2010), novel structural systems

42 that are not yet implemented in NBCC can be designed using the "alternative solutions" path, 
43 provided that the novel solution provides the same level of performance as specified for the already

44 included "acceptable solutions". This approach allows for use of innovative wood construction if 45 technical information and design guidance on new ductile wood-based structural systems can be 46 provided.

Steel, concrete, and wood have different structural properties, and by combining them in a 48 hybrid structural system each material can be placed where their inherent advantages are developed 49 while diminishing their limitations. Steel elements, for example, can dissipate large amounts of 50 energy under cyclic loads when properly designed, and hence steel structures exhibit ductile 51 behaviour during earthquakes (FEMA 2000a; FEMA 2000b). Wood on the other hand has a high 52 strength to weight ratio, especially when compared to concrete and exhibits ductile behaviour in 53 compression parallel and perpendicular to grain, while it has brittle failure modes in tension 54 parallel and perpendicular to grain and shear parallel to the grain (Dinwoodie 2000). Since 55 earthquake induced forces are proportional to the weight of the building, timber based buildings 56 attract lower seismic forces; ductile connections, however, are required to dissipate the seismic 57 input energy. Steel elements used in wood-based hybrid buildings can provide additional ductility, 58 thus improving the overall seismic performance of wood-based hybrid buildings (Moore 2000). In

59 the same vein, reinforced concrete has high compression and bending strength and can be used in 60 constructing elevator shafts in wood-hybrid buildings. A most prominent example of a tall hybrid 61 wood-concrete building in Canada is Brock Commons, the 18-storey student residence building 62 currently under construction at the University of British Columbia in Vancouver (Poirier et al. 63 2016). Over the last decade, several innovative hybrid systems were proposed to promote the use 64 of timber in large-scale construction. One such system uses steel moment resisting frames with 65 CLT panels as infill (Dickof et al. 2014). 
Another innovative hybrid system is the 'Finding Forest Through Trees' (FFTT) structural system, see Figure 1 (left), which consists of balloon-type vertical mass timber wall panels such as CLT that run the height of the building and are anchored down using hold-downs and rigid shear connectors (Green and Karsh 2012). Four FFTT design options for different recommend story heights are proposed. Option 1 for structures up to 12 storeys consists of mass timber core walls,

71 glulam perimeter columns and embedded steel beams as lateral load resisting system (LLRS).

72 Option for building up to 20 storeys includes additional interior structural walls. Option 3 utilizes mass-timber for core and exterior structural walls as LLRS, see Figure 1. Option-4 pushes the maximum building height up to 30 storeys by utilizing structural mass-timber for core, exterior and interior walls as LLRS. For all three options, horizontal steel beams are partially embedded into the CLT panel (and into the Glulam columns) to transfer lateral loads and provide ductility, see Figure 1b. These steel beams are designed to act as the ductile weak link that develop plastic hinges and trigger a "strong-column weak-beam" failure mechanism. For more FFTT system design details, the reader is kindly referred to the Tall Wood Report (Green and Karsh 2012).

Experimental investigations on the system were carried out at the University of British Columbia as part of two MASc theses (Bhat 2013; Azim 2014; Bhat et al. 2014). A subsequent numerical study on the potential force reduction factors for the FFTT system (Zhang et al. 2015) was based on design option-1 of the FFTT system for buildings up to 12 stories. Utilizing finite

84 element models with four different building heights (3, 6, 9 and 12 stories), potential $R_{d}$ factors 85 were derived through limiting the inter-storey drift $(2.5 \%$ drift with $90 \%$ probability of nonexceedance) using nonlinear time history dynamic analyses. Based on the empirical cumulative

87 distribution functions of maximum inter-story drift for the verified model of a system prototype, a 88 ductility factor $R_{\mathrm{d}}=\mathrm{f} 5.0$ was suggested for the considered layout of the FFTT system. 
The objective of the research presented in this paper is to determine an appropriate layout

90 for the steel beam to CLT panel connection. To achieve this objective, different layouts were tested 91 under quasi-static monotonic and reversed cyclic loading.

\section{2. Experimental Investigation}

\section{$93 \quad$ 2.1 Description of the Connection Assemblies}

94 The test specimens of the FFTT connections, as schematically shown in Figure 2 and photos shown

95 in Figure 3, consisted of 7-ply CLT panels with embedded steel beams. The CLT panel dimensions

96 were: $L_{\mathrm{CLT}}=3,000 \mathrm{~mm}, B_{\mathrm{CLT}}=900 \mathrm{~mm}$ wide and $T_{\mathrm{CLT}}=239 \mathrm{~mm}$, as labelled in Figure 2 . Seven

97 test series with different embedment lengths $\left(e_{1}\right)$ and embedment depths $\left(e_{\mathrm{d}}\right)$ of the steel beams

98 were designed as summarized in Table 1. The embedment length is measured inside the CLT panel

99 in the direction of the steel beam, while the embedment depth is the distance the steel cross section

100 penetrates into the edge thickness of the CLT panel.

101 Series S1 and S2 utilized Class II wide-flange steel beams W150×14, and the embedment

102 depth was $50 \mathrm{~mm}$ for S1 and $100 \mathrm{~mm}$ for S2 (Figures $3 \mathrm{~b}$ and 3c). For series S3, the flange width of

103 the Class II steel beam was reduced to $89 \mathrm{~mm}$ (resulting in $16 \%$ reduction in cross sectional area to

104 induce yielding at a lower load level (Figure 3d). Series S4 (Figure 3e) and S5 (Figure 3f) used

105 HSS $(100 \times 50 \times 3.175)$ steel beam with different embedment lengths $(600 \mathrm{~mm}$ and $300 \mathrm{~mm})$.

106 Series S6 (Figure 3g) and S7 (Figure 3h) also utilized wide-flange steel beams, as with S1

107 and S2, but in this case beams with Class I bending section type were selected (W100×19).

108 Furthermore, steel bearing plates and internal stiffeners (ASTM A992 flat steel 150×100×6.25 mm

109 and $87 \times 50 \times 6.25 \mathrm{~mm}$, respectively) were used in series S6 and S7 to specify the internal lever arm

110 in the CLT panels and avoid premature buckling of the profile. Configuration S6 has embedded 
111 length of $500 \mathrm{~mm}$ inside CLT panel and an embedment depth of $85 \mathrm{~mm}$. Configuration S7 had

$112900 \mathrm{~mm}$ embedment length with an embedment depth of $100 \mathrm{~mm}$.

113 The main parameters of the specimens of each test series are summarized in Table 1. The

114 beams were placed into pre-cut slots in the CLT panels and held in place using two $9.5 \mathrm{~mm} \mathrm{lag}$

115 bolts in pre-drilled holes. Three specimens per test series were produced and subsequently tested.

$116 \quad 2.2$ Materials

117 The CLT samples were cut from a commercial product, CrossLam ${ }^{\mathrm{TM}}$ SLT3, that meets the 118 requirements of the CLT manufacturing standard ANSI/APA PRG 320 (2011). The CLT panel was 119 produced of SPF (Spruce-Pine-Fir) grade No.1 and No.2 with the two outer layer being $32 \mathrm{~mm}$ 120 thick and the five inner layers $35 \mathrm{~mm}$ each, for a total thickness of $239 \mathrm{~mm}$. For Series S1, S2, S3, 121 S6 and S7, wide-flange steel profiles of ASTM A992 mild-steel with a yield strength of $350 \mathrm{MPa}$ 122 were used. For Series S4-S5, HSS profiles of ASTM A500 Grade B steel were used with a yield 123 strength of $300 \mathrm{MPa}$ and a modulus of elasticity of $210 \mathrm{GPa}$.

\section{$124 \quad 2.3$ Methods}

125 The CLT panels were placed horizontally on the test floor and were bolted to the test floor at both 126 ends to restrain them from translation, rotation or uplift. The load was applied by means of a 127 hydraulic actuator at the end of the projecting steel beam at a distance of $L=762 \mathrm{~mm}$ from the 128 edge of the CLT panel (50 mm away from the free end of the beam). For test series S1-S5, six 129 Linear Variable Differential Transformers (LVDT) (labelled 1 to 6) along the steel beam were 130 mounted to measure the relative horizontal displacement between beam and panel, see Figure 2 131 (top). For series S6 and S7, four LVDT were attached to the embedded beam with the first LVDT 132 placed $152.4 \mathrm{~mm}$ from the edge of the panel and the two LVDTs inside the CLT panel located at 
133 the centre of bearing plates, see Figure 2 (bottom). The LVDTs placed on the cantilever portion

134 were located $350 \mathrm{~mm}$ and $700 \mathrm{~mm}$ away from the beam-wall interface.

135 The tests were conducted at the FPInnovations' Advanced Building Systems Laboratory in

136 Vancouver. The quasi-static monotonic load was applied at a constant rate of $12.7 \mathrm{~mm} / \mathrm{minute}$.

137 This displacement rate created a beam rotation of $0.9 \% \mathrm{~min}$ and resulted in a test duration of

138 approximately ten minutes. In the revised cyclic tests, the CUREE loading protocol according to

139 ASTM E2126 (2009) method C was used by applying grouped displacement cycles. Each load

140 group consists of primary cycles in increments of $20 \%$ of the reference deformation from the

141 monotonic tests and two follower cycles at $75 \%$ of the displacement of the primary cycle, as shown

142 in Figure 4.

143 Two replicates for each series were tested under quasi-static monotonic loading, while a

144 third specimen was tested under reversed cyclic loading. From the recorded applied load $(F)$ and

145 the displacement of the beam $(D)$, the applied moment and the resulting beam rotation were

146 obtained according to Eq. 1 where $(L)$ is the length of the beam:

$$
M=F \times L ; \quad R=D / L
$$

Eq. 1

148 The yield moment $\left(M_{\mathrm{Y}}\right)$ and rotation at yield $\left(R_{\mathrm{Y}}\right)$, the maximum moment $\left(M_{\mathrm{M}}\right)$ together with its

149 corresponding rotation $\left(R_{\mathrm{M}}\right)$, as well as the rotation at failure $\left(R_{\mathrm{U}}\right)$ when the load dropped to $80 \%$ of

150 maximum) were determined. The connection initial rotational stiffness, $k$, was computed for the

151 loading range of $10 \%$ to $40 \%$ according to EN-26891:

$$
k=\frac{0.4 M_{\mathrm{M}}-0.1 M_{\mathrm{M}}}{0.4 R_{\mathrm{M}}-0.1 R_{\mathrm{M}}}
$$

153 The connection ductility, $\mu$, was calculated as the ratio between the rotation at capacity and the 154 yield rotation from the load-displacement curves: 


$$
\mu=\frac{R_{\mathrm{U}}}{R_{\mathrm{Y}}}
$$

156 In revised cyclic tests, the CUREE loading protocol (ASTM E2126-09 (2009) was used applying

157 grouped displacement cycles where each group consists of primary cycles in increments of $20 \%$ of

158 the reference deformation from the monotonic tests and two follower cycles at $75 \%$ of the

159 displacement of the primary cycle. The reference deformation was given by the value which was

160 obtained when the load dropped to $80 \%$ of the peak load. The cyclic tests were conducted at a

161 loading rate of $5 \mathrm{~mm} / \mathrm{min}$ (equitant to a rotation of the beam of $0.007 \mathrm{rad} / \mathrm{min}$ ). The yield point

162 moment and rotation $\left(M_{\mathrm{Y}}\right.$ and $\left.R_{\mathrm{Y}}\right)$ were determined by developing an idealized equivalent energy

163 elastic-plastic (EEEP) curve based on the first cyclic envelope, following the procedure outlined in 164 ASTM E2126 (2009):

$$
M_{\mathrm{Y}}=\left(D_{\mathrm{U}}-\sqrt{D_{\mathrm{U}}^{2}-\frac{2 A}{k}}\right) k
$$

166 Where $D_{\mathrm{u}}$ is the ultimate displacement; $A$ is the total area under the curve from zero to the ultimate 167 load, and $k$ is the elastic stiffness.

The hysteretic energy dissipated by a system or connection undergoing quasi-static or 169 dynamic loading represents a performance measure when subjected to seismic loads (Karacabeyli 170 and Popovski 2003). Since there is a positive correlation between the dissipated hysteretic energy 171 and the inelastic deformation demands, stable hysteretic loops with large energy dissipative 172 capacity at the connection level provide a better deformation performance of the system. This is 173 often observed during cyclic tests, where if two systems with similar strength are tested under the 174 same cyclic loading protocol, the one with the higher energy absorption, i.e., "fuller" hysteresis 175 loops, exhibits superior seismic performance. Thus, dissipated energy is a term that has become 
176 synonymous to performance. Herein, the total cumulative dissipated energy in the reversed cyclic 177 tests $(E)$ was calculated according to Eq.5:

$$
E=\sum_{i=1}^{n} A_{i}
$$

179 Where $\left(A_{i}\right)$ presents the area within the hysteresis loop under each load cycle.

\subsection{Results and discussion monotonic tests}

181 The moment-rotation curves of the steel beams for each test specimen are shown in Figure 5. The 182 plots are based on the rotations obtained from LVDT-6 (S1-S5) and LVDT-4 (S6-S7) placed at the 183 cantilever end of the beam. The results are also summarized in Table 2. Figure 5 illustrates the

184 differences in behaviour between the series which can be grouped into three categories: S1-S2-S3, S4-S5, and S6-S7.

Series S1, S2 and S3 utilized wide flange steel beams and exhibited similar stiffness, yield point and ductility irrespective of the variations in beam embedment. The different embedment, however, led to differences in failure modes as illustrated in the photos in Figure 6. Connection assemblies with fully embedded beams performed better compared to the partially embedded Isections. The beam yielding occurred at the panel-beam interface at the exposed side of the top

191 (tension) flange, while the in-plane movement of the beam caused negligible wood crushing at the

192 interface. In case of assembly S1, the tendency of the beam to deform out of the loading plane

193 beyond yielding resulted in pull-out of wood material below the embedded portion of the beam 194 near the wall-beam interface (Figure 6a). In case of S2, not much wood pull-out occurred beneath 195 the embedded beams, however a crack in the layer below the embedded beam was observed 196 (Figure 6b). The yielding of the beam led the cantilever end to lift up near the interface (Figure 6c) 
198 section) showed an increase in yield and ultimate rotation. Beam yielding occurred at the point of

199 cross-section reduction at the exposed side of the top flange (Figure 6d). Overall, the differences

200 between series S1-S3 were relatively small. Past yielding, the stiffness quickly degraded and

201 changes in the embedment depth did not have any effect. With an average ductility of 2.6, the I-

202 flange beams in series S1-S3 do not facilitate ductile behaviour.

Series S4 and S5 utilized hollow section steel beams with different embedment lengths and

204 exhibited a different behaviour compared to the other series. Yield moment, ultimate moment and

205 stiffness of these two series were significantly lower. Beam yielding of the HSS sections occurred

206 at the beam-wall interface at a bending moment of that was only $40 \%$ of that of the assemblies with

207 wide flange steel beams. The stiffness was also significantly reduced; ductility, however, was

208 higher for the assemblies in series S4-S5. The connection assemblies were able to retain the load-

209 carrying capacity long after yielding and displayed a flat post-yield curve. The maximum rotations

210 increased more than three times compared to the wide flange I-sections. Due to uniform bearing of

211 on the CLT panel, yielding occurred symmetrically on both faces (Figures 6e). Neither beam uplift

212 nor withdrawal of lag bolts was observed. However, wood crushing of up to $10 \mathrm{~mm}$ was recorded

213 at the interface in the layer with grain orientation perpendicular to the load (Figure 6f).

214 Assemblies in series S6 and S7 utilized small cross section wide flange steel beams with

215 additional steel bearing plates. The obtained yield moment, ultimate moment, stiffness and ductility

216 for these assemblies were higher compared to the other test series. Both S6 and S7 series exhibited

217 well defined yield points (Figure 6g) at similar bending moments. The ultimate moment and 218 stiffness for S6 was slightly higher than that for S7. As can be seen from Figure 5, the S7

219 configuration could also undergo larger rotations than S6 leading to increased ductility. In both

220 cases, the deformations inside the CLT panel were small (around $2 \mathrm{~mm}$ ). However, the S6 series 
221 exhibited rolling shear failure because the flanges penetrated into the fourth layer of the CLT panel 222 oriented perpendicular to the grain, see Figure $6 \mathrm{~g}$. The partial embedment in series $\mathrm{S} 7$ helped to 223 avoid this highly undesirable failure mode and led to a significant increase in ductility.

Table 2 includes a comparison between the experimentally observed yield and maximum moments and the calculated yield and maximum moments, considering full plastic cross sections.

226 While for the Class II cross section of series S1-S3, both the yield and the plastic moment are in

227 very close agreement with the expectations, some discrepancies in the connections with HSS were 228 observed. The moment-rotation curves of the HSS section in series S4-S5 did not exhibit a clear

229 yield point but a slow deviation from linearity; the experimentally determined maximum moment,

230 however, was relatively close to the theoretical plastic moment. For series S6-S7, clearly defined

231 yield points were observed and the experimental and theoretical yield moment were in good

232 agreement. The plastic moment, however, was significantly lower than the experimentally obtained 233 maximum moment, which can be explained by the fact that buckling was prevented by adding steel 234 plates.

\section{$235 \quad 2.5$ Results and discussion reversed cyclic tests}

236 The moment-rotation curves obtained from the cyclic tests are illustrated in Figure 7; the results

237 obtained from the positive and negative first cycle envelope curves are summarized in Table 3 . The

238 failure modes, illustrated in Figure 8, were very similar to those observed in the monotonic tests.

239 The moment capacity and stiffness of the embedded steel beam connection for all seven test series

240 followed a similar trend like in the monotonic tests. While capacity, stiffness and ductility were

241 similar for assemblies of series S1-S3, the dissipated energy in series S2 was significantly (four

242 times) higher than that for series S1 and S3. This suggests that reduction of the embedment depth

243 (S1) or reduction in the beam cross section (S3), leads to a less-desirable performance. The 
244 behaviour under cyclic loads confirmed that the beam plastification is the most important factor

245 contributing towards the ductility of the assembly. The CLT panels behaved as rigid members and

246 resisted the in-plane wood deformation under the beam bearing, dissipating little energy. Series S1

247 underwent the fewest cycles before failure occurred as pull-out of the embedded portion of the

248 beam accompanied by wood splitting, as illustrated by Figure 8a. Loading was continued only until

$24970 \%$ of the target displacement since the lag bolts began withdrawing before the onset of beam

250 yielding. The yield and maximum moments were similar between positive and negative sides but

251 the stiffness and ductility on the positive side were slightly higher. Significant wood pull-out (plug-

252 shear failure) was observed in series S2, as shown in Figure 8b. The cyclic load was continued

253 until achieving $100 \%$ of target displacement. Since the actuator was not anchored, significant uplift

254 and yielding out of plane was observed at the cantilever end of the beam. The cyclic loading for

255 series S3 was continued until achieving 100\% of target displacement. The stiffness is the highest

256 among S1-S3, but the ductility is similar to series S1. The embedded end of the beam was properly

257 held in place. The eccentricity due to the non-symmetric beam yielding in assemblies S2 and S3

258 resulted in out-of-plane buckling, see Figure 8c, and decreased the in-plane deformation capacity

259 of the system. We have focused on the in-plane behaviour of the frames in each main direction in

260 this study. The out of plane behaviour is more related to pure steel bending and can be easily

261 predicted by analytical models that will be developed for a 3-D structure. Furthermore, in a real

262 structure, the out of plane behaviour in one direction will be resisted by in-plane behaviour of the

263 frame in the perpendicular direction.

Series S4 and S5 were tested with a smaller HSS section, and hence exhibited lower yield

265 and ultimate moments. These sections, however, do provide significantly higher ductility and

266 showed no decrease in ductility when comparing their cyclic tests to their monotonic tests. Failure 
267 in series S4 was pure steel yielding, as shown in Figure 8d. Furthermore, the large deformation 268 capacity of these beams also increase the energy dissipation. The hysteresis loops were large, 269 implying a connection with adequate ductility for the desired seismic application. The hysteresis 270 behaviour of the beam in the embedded portion was linear and the nonlinearity in the system was 271 provided by the yielding at the interface and in-plane deformation of the cantilever portion of the 272 beam. Series S5, which utilized beams with reduced embedment length, did not lead to any 273 differences in yield and ultimate moment. However, the reduced embedment length led to wood 274 crushing, see Figure 8e, and subsequent pinching in the hysteresis loop.

Series S6 and S7 reached higher moment capacity and stiffness because of the use of the

276 Class I W sections along with steel bearing plates and side plates. These Class I W sections were 277 able to experience full plasticity and to maintain their plastic moment over larger rotations. For 278 series S6, the cyclic loading was continued until achieving $150 \%$ of target displacement. The 279 failure mode in this case consisted of rolling shear in the fourth laminate of CLT member along 280 with crushing of wood, see Figure 8e. This undesirable failure was caused by the larger loads that 281 the beams transferred before buckling and was avoided in series S7, by adding steel bearing plates, 282 the larger lever arm of the longer embedment and the fact that the steel beam did not end close to 283 the weak CLT cross layer. The load for series S7 was continued until $160 \%$ of target displacement 284 and the assembly behaviour was more ductile, with typical steel hysteresis loops, implying that the 285 connection has an adequate behaviour for seismic applications. While the capacity and the stiffness 286 were purely driven by the beam cross section and were very similar between series S6 and S7, the 287 partial embedment used in series S7 lead to higher ductility and increased energy dissipation. 


\subsection{Conclusions}

289 The component level performance of a newly proposed wood-steel hybrid structural system named 290 FFTT was investigated. Full-size 7-ply CLT panels with embedded steel beams were tested under 291 quasi-static monotonic and reversed cyclic loading to investigate the effects of the chosen beam

292 profile, beam embedment length and embedment depth. From the results presented in this paper the 293 following main conclusions can be drawn:

294 1) The connection assemblies using embedded steel beams were able to obtain the desired ductile 295 beam failure mechanism at the CLT wall intersection;

296 2) The type of steel profile had a significant impact on performance of the assemblies; wide flange 297 W sections achieved much higher moment capacities than HSS sections. HSS sections, 298 however, provided much higher ductility and were not prone to out-of-plane buckling;

299 3) The use of Class I wide flange cross sections, in addition to steel bearing plates, provided the 300 best performance of any tested assembly. In this case, high capacity and stiffness were $301 \quad$ combined with a moderate ductility;

302 4) The embedment depth of the steel beam was also an important factor that influenced the 303 behaviour of the assemblies. To avoid local rolling shear failure in the CLT, the edge of the steel 304 beam should not end in a perpendicular CLT layer. The tested assemblies with smaller 305 embedment depth combined with full embedment length exhibited superior performance to 306 those with larger embedment depth, but reduced embedment length;

307 5) The connection performance in the cyclic tests was similar in terms of yield moment, maximum 308 moment and stiffness to that obtained during the static tests. Most of the energy was dissipated 309 as a result of the deformation of the cantilever portion of the embedded steel beam. The ductility 310 obtained during the cyclic tests, however, was lower than that obtained during the static tests. 
311 The experimental investigation demonstrated that appropriate connection layouts can lead to 312 desired steel failure mechanism while avoiding excessive crushing of the CLT panels. The tests

313 thereby confirmed the feasibility of the FFTT timber-steel hybrid system to dissipate energy for the

314 seismic design. While it seems premature for the system to be applied in the design of actual

315 buildings, the research presented herein serves as a precursor for developing design guidelines for

316 the FFTT system as an option for tall wood-hybrid building systems. 


\section{Acknowledgements}

This research was supported by the Natural Sciences and Engineering Research Council of Canada (NSERC) through grant \#NETGP 386472 and the Wood First Program by Forestry Innovation Investments. The support from Johannes Schneider and Paul Simmons of FPInnovations is also acknowledged.

\section{References}

APA-The Engineered Wood Association - ANSI/APA PRG 2011. APA - The Engineered Wood Association. Standard for Performance-Rated Cross Laminated Timber. Tacoma, USA.

ASTM, 2009. E2126-09Standard Test Methods for Cyclic (Reversed) Load Test for Shear Resistance of Walls for Buildings. American Society for Testing and Materials, West Conshohocken, USA.

Azim M.R., 2014. Numerical and experimental investigations of connection for the timber-steel hybrid system. MASc thesis, Department of Civil Engineering, University of British Columbia, Vancouver, Canada.

Bhat P., 2013. Experimental investigation of connection for the FFTT timber-steel hybrid system. MASc thesis, Department of Civil Engineering, University of British Columbia, Vancouver, Canada.

Bhat P., Azim R., Popovski P., Tannert T., 2014. Experimental and numerical investigation of novel steel-timber-hybrid system. In Proceedings of the World Conference on Timber Engineering, Quebec City, Canada. 
Buchanan A., Ostman B. and Frangi A., 2014. Fire resistance of timber structures. National Institute of Standards and Technology Report, Gaithersburg.

Ceccotti, A., Sandhaas, C. and Yasumura, M., 2010. Seismic behaviour of multistory crosslaminated timber buildings. In International Convention of Society of Wood Science and Technology, Geneva, Switzerland, October 2010.

CEN, 1991. EN 26891 Timber structures-Joints made with mechanical fasteners-General principles for the determination of strength and deformation characteristics, European Committee for Standardization, Bruxelles, Belgium.

Dickof, C., Stiemer, S.F., Tesfamariam, S. and Wu, D., 2012, July. Wood-steel hybrid seismic force resisting systems: seismic ductility. In Proceedings of the World Conference for Timber Engineering, Auckland, New Zealand.

FEMA (Federal Emergency Management Agency), 2000. Recommended Specifications and Quality Assurance Guidelines for Steel Moment Frame Construction for Seismic Applications. FEMA-353. Washington DC, USA.

FEMA (Federal Emergency Management Agency), 2000. State of the Art Report on Past Performance of Steel Moment Frame Buildings in Earthquakes. FEMA-355E. Washington DC, USA.

Fragiacomo, M., Dujic, B. and Sustersic, I., 2011. Elastic and ductile design of multi-storey crosslam massive wooden buildings under seismic actions. Engineering structures, 33(11), pp.3043-3053.

Gavric, I., Fragiacomo, M., and Ceccotti, A., 2015. Cyclic Behaviour of Typical Metal Connectors for Cross-laminated (CLT) Structures. Materials and Structures 48(6): 1841-1857. 
Green M.C. and Karsh J.E., 2012. TALL WOOD - The case for tall wood buildings. Report prepared for the Canadian Wood Council on behalf of the Wood Enterprise Coalition and Forest Innovation Investment, Vancouver, BC.

Karacabeyli E. and Lum C., 2014. Technical Guide for the Design and Construction of Tall Wood Buildings in Canada. FPInnovations Special Publication SP-55E. Pointe-Claire, Québec, FPInnovations, Canada..

Karacabeyli, E. and Popovski, M., 2003. Design for earthquake Resistance. Timber Engineering, 267-299.

Moore, M., 2000. Scotia Place - 12 Story Apartment Building A Case Study of High-Rise Construction Using Wood and Steel. New Zealand Timber Design Journal, 10(1): 5-12.

Mohamad, N. A., 2015. Application of Analysis Tools from NEWBuildS Research Network in Design of a High-Rise Wood Building. Special Publication. Available from www.bcfii.ca. [accessed 9 March 2017].

NRCC (National Research Council of Canada),2010. National Building Code of Canada 2010. Canada Commission on Building and Fire Code, Ottawa, Canada.

Dinwoodie, J.D., 2002. Timber: its nature and behaviour. CRC Press, London.

Pei, S., Popovski, M., and van de Lindt, J.W., 2013. Analytical Study on Seismic Force Modification Factors for Cross-laminated Timber Building for NBCC. Canadian Journal of Civil Engineering, 40(9): 887-896.

Poirier E., Moudgil M., Fallahi A., Staub-French S. and Tannert T., 2016. Design and Construction of a 53 Meter Tall Timber Building at The University Of British Columbia. In Proceedings of the World Conference on Timber Engineering, Vienna, Austria. 
Professner, H. and Mathis, C., 2012. LifeCycle Tower-High-Rise Buildings in Timber. Structures Congress. 1980-1990.

Skidmore, O. and Merrill, L.L.P., 2013. Timber tower research project: final report. Available from www.som.com [accessed 9 March 2017].

Smith, I. and Frangi, A., 2014. Use of timber in tall multi-storey buildings. Structural Engineering Document SED, 13. International Association for Bridge and Structural Engineering, ISBN 978-385748-133-8, Zurich, Switzerland.

Zhang, X., Fairhurst, M. and Tannert, T. (2015). Ductility Estimation for a Novel Timber-SteelHybrid System. Journal of Structural Engineering. 142(4), p. E4015001. 


\section{Tables}

Table 1: Test configurations

\begin{tabular}{cccc}
\hline Series & Steel profile & $e_{1}[\mathrm{~mm}]$ & $e_{\mathrm{d}}[\mathrm{mm}]$ \\
\hline S1 & W 150 & 900 & 50 \\
S2 & W 150 & 900 & 100 \\
S3 & W 150 & 900 & 100 \\
S4 & HSS 100 & 900 & 50 \\
S5 & HSS 100 & 600 & 50 \\
S6 & W 100 & 500 & 100 \\
S7 & W 100 & 900 & 85 \\
\hline
\end{tabular}

Notes: 1) Cross section reduced 
Table 2: Summary of monotonic test results

\begin{tabular}{cccccccccc}
\hline Series & $\begin{array}{c}M_{\mathrm{Y}, \mathrm{a}} \\
{[\mathrm{kN} . \mathrm{m}]}\end{array}$ & $\begin{array}{c}M_{\mathrm{M}, \mathrm{a}} \\
{[\mathrm{kN} . \mathrm{m}]}\end{array}$ & $\begin{array}{c}M_{\mathrm{Y}} \\
{[\mathrm{kN} . \mathrm{m}]}\end{array}$ & $\begin{array}{c}M_{\mathrm{M}} \\
{[\mathrm{kN} . \mathrm{m}]}\end{array}$ & $\begin{array}{c}R_{\mathrm{Y}} \\
{\left[{ }^{0}\right]}\end{array}$ & $\begin{array}{c}R_{\mathrm{M}} \\
{\left[{ }^{0}\right]}\end{array}$ & $\begin{array}{c}R_{\mathrm{U}} \\
{\left[{ }^{0}\right]}\end{array}$ & $\begin{array}{c}k \\
{\left[\mathrm{kN} . \mathrm{m} /{ }^{0}\right]}\end{array}$ & $\begin{array}{c}\mu \\
{[-]}\end{array}$ \\
\hline S1 & & & 29.9 & 33.4 & 1.5 & 2.1 & 3.9 & 18.2 & 2.6 \\
S2 & 31.6 & 34.6 & 31.9 & 34.4 & 1.5 & 2.1 & 3.9 & 20.5 & 2.7 \\
S3 & & & 33.4 & 34.2 & 1.8 & 2.0 & 4.6 & 16.4 & 2.6 \\
\hline S4 & \multirow{2}{*}{8.1} & \multirow{2}{*}{12.2} & $13.1^{1)}$ & 14.1 & $2.6^{1)}$ & 4.4 & 9.1 & 6.9 & 3.5 \\
S5 & & & $13.0^{1)}$ & 14.4 & $3.4^{1)}$ & 6.1 & 13.3 & 5.4 & 3.9 \\
\hline S6 & \multirow{2}{*}{32.9} & \multirow{2}{*}{37.5} & 36.9 & 46.7 & 1.5 & 4.5 & 4.5 & 31.2 & 3.1 \\
S7 & & & 33.8 & 40.3 & 1.8 & 13.7 & 14.0 & 21.7 & 7.7 \\
\hline
\end{tabular}

Note: 1) No clearly defined yield point observed in tests 
Table 3: Summary of reversed cyclic test results

\begin{tabular}{|c|c|c|c|c|c|c|c|c|}
\hline & $\begin{array}{c}M_{\mathrm{Y}} \\
{[\mathrm{kN} . \mathrm{m}]}\end{array}$ & $\begin{array}{c}M_{\mathrm{M}} \\
{[\mathrm{kN} . \mathrm{m}]}\end{array}$ & $\begin{array}{l}R_{\mathrm{Y}} \\
{\left[{ }^{0}\right]} \\
\end{array}$ & $\begin{array}{l}R_{\mathrm{M}} \\
{\left[{ }^{0}\right]}\end{array}$ & $\begin{array}{l}R_{\mathrm{U}} \\
{\left[{ }^{0}\right]}\end{array}$ & $\begin{array}{c}k \\
{\left[\mathrm{kN} \cdot \mathrm{m} /{ }^{0}\right]}\end{array}$ & $\begin{array}{l}\mu \\
{[-]}\end{array}$ & $\begin{array}{c}E \\
{[-]}\end{array}$ \\
\hline $\mathrm{S} 1$ & $\begin{array}{r}31.5 \\
(34.2) \\
\end{array}$ & $\begin{array}{r}33.8 \\
(35.6) \\
\end{array}$ & $\begin{array}{r}1.7 \\
(2.5) \\
\end{array}$ & $\begin{array}{r}2.6 \\
(3.2) \\
\end{array}$ & $\begin{array}{r}3.4 \\
(3.6) \\
\end{array}$ & $\begin{array}{r}19.0 \\
(15.0) \\
\end{array}$ & $\begin{array}{r}2.0 \\
(1.4) \\
\end{array}$ & 219 \\
\hline $\mathrm{S} 2$ & $\begin{array}{r}35.0 \\
(33.6) \\
\end{array}$ & $\begin{array}{r}39.9 \\
(37.1) \\
\end{array}$ & $\begin{array}{r}1.2 \\
(1.9)\end{array}$ & $\begin{array}{r}2.6 \\
(2.4)\end{array}$ & $\begin{array}{r}4.1 \\
(5.6)\end{array}$ & $\begin{array}{r}29.0 \\
(17.5) \\
\end{array}$ & $\begin{array}{r}3.4 \\
(2.9)\end{array}$ & 1091 \\
\hline $\mathrm{S} 3$ & $\begin{array}{r}( \\
(33.0) \\
\end{array}$ & $\begin{array}{r}33.2 \\
(36.1) \\
\end{array}$ & $\begin{array}{r}0.7 \\
(1.4)\end{array}$ & $\begin{array}{r}1.6 \\
(2.6)\end{array}$ & $\begin{array}{r}1.6 \\
(4.0)\end{array}$ & $\begin{array}{r}25.7 \\
(23.5)\end{array}$ & $\begin{array}{r}2.1 \\
(2.9) \\
\end{array}$ & 255 \\
\hline $\mathrm{S} 4$ & $\begin{array}{r}12.5 \\
(12.9) \\
\end{array}$ & $\begin{array}{r}13.7 \\
(13.9) \\
\end{array}$ & $\begin{array}{r}2.1 \\
(1.8) \\
\end{array}$ & $\begin{array}{r}3.6 \\
(3.6) \\
\end{array}$ & $\begin{array}{r}7.2 \\
(8.1) \\
\end{array}$ & $\begin{array}{r}6.1 \\
(7.2) \\
\end{array}$ & $\begin{array}{r}3.5 \\
(4.5) \\
\end{array}$ & 1211 \\
\hline S5 & $\begin{array}{r}11.4 \\
(12.9) \\
\end{array}$ & $\begin{array}{r}13.3 \\
(14.5) \\
\end{array}$ & $\begin{array}{r}2.7 \\
(2.9) \\
\end{array}$ & $\begin{array}{r}8.5 \\
(9.0) \\
\end{array}$ & $\begin{array}{r}13.5 \\
(15.6) \\
\end{array}$ & $\begin{array}{r}4.3 \\
(4.5) \\
\end{array}$ & $\begin{array}{r}5.1 \\
(5.5) \\
\end{array}$ & 1609 \\
\hline S6 & $\begin{array}{r}36.4 \\
(40.7) \\
\end{array}$ & $\begin{array}{r}45.1 \\
(46.7) \\
\end{array}$ & $\begin{array}{r}1.3 \\
(1.9)\end{array}$ & $\begin{array}{r}2.3 \\
(3.6)\end{array}$ & $\begin{array}{r}2.3 \\
(3.6)\end{array}$ & $\begin{array}{r}21.4 \\
(21.4) \\
\end{array}$ & $\begin{array}{r}1.8 \\
(1.9)\end{array}$ & 746 \\
\hline S7 & $\begin{array}{r}37.1 \\
(37.4)\end{array}$ & $\begin{array}{r}40.2 \\
(40.5)\end{array}$ & $\begin{array}{r}1.9 \\
(1.8)\end{array}$ & $\begin{array}{r}3.7 \\
(5.4)\end{array}$ & $\begin{array}{r}3.8 \\
(5.6)\end{array}$ & $\begin{array}{r}18.7 \\
(21.1)\end{array}$ & $\begin{array}{r}2.1 \\
(3.1)\end{array}$ & 1386 \\
\hline
\end{tabular}

Note: values in parenthesis are for negative side of the hysteresis loop 


\section{Figure Captions}

Figure 1: Proposed FFTT system (left), detail of CLT-panel steel beam interface (middle) and proposed floor plan (right)

Figure 2: Test specimen: schematic from series S1-S5 (top) and series S6-S7 (bottom)

Figure 3: Photos of test specimens: a) general set-up; b) series S1; c) series S2; d) series S3; e) series S4; f) series S5; g) series S6; and h) series S7

Figure 4: Moment-rotation curves from quasi-static monotonic tests

Figure 4: Reversed cyclic loading protocol

Figure 6: Failed test specimens after monotonic loading: a) and b) cracking of wood in S1 and S2;

c) out-of-plane displacement in S1 and S2; d) localized yielding in S3; e) symmetric beam yielding in S4; f) beam yielding and wood crushing in S5; g) beam yielding in S6 and S7; g) rolling-shear in S6

Figure 7: Moment-rotation curves from reversed cyclic tests

Figure 8: Failed test specimens after reversed cyclic loading: a) S1-Wood splitting; b) S2-Wood plug-shear failure; c) S3-Beam uplift; d) S4- Beam yielding; e) S5-Beam yielding and wood crushing; f) S6-Rolling shear crack 
Figure 1:

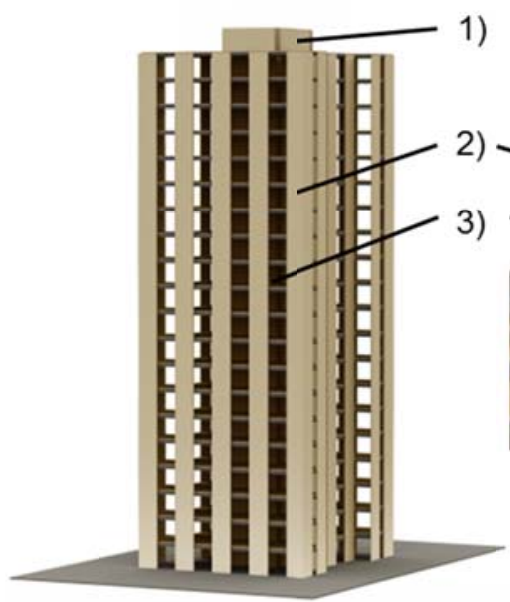

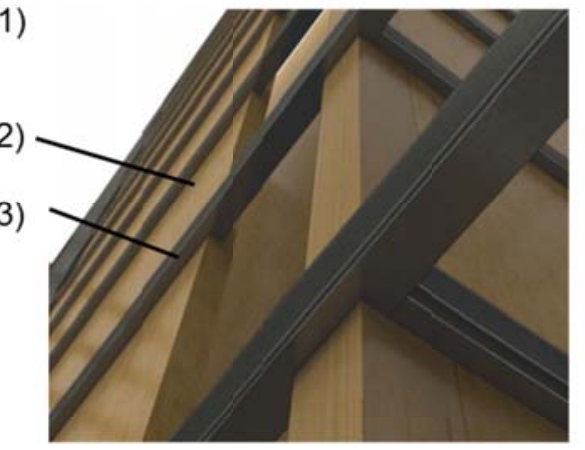

1) Mass-timber core

2) Mass-timber wall

3) Steel beam

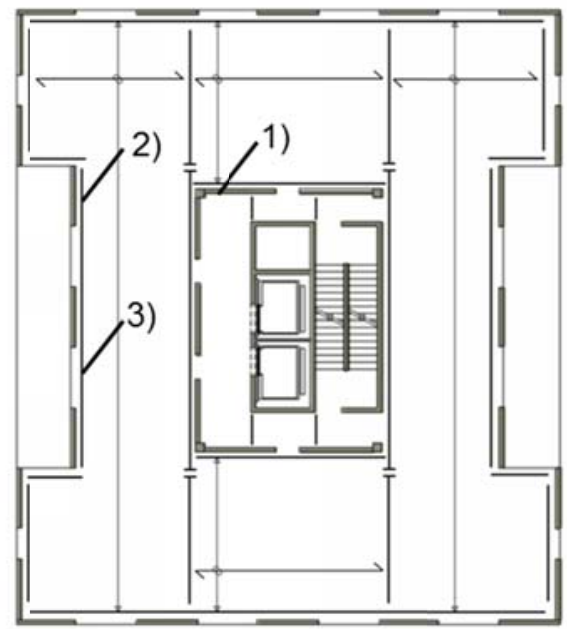


Figure 2:

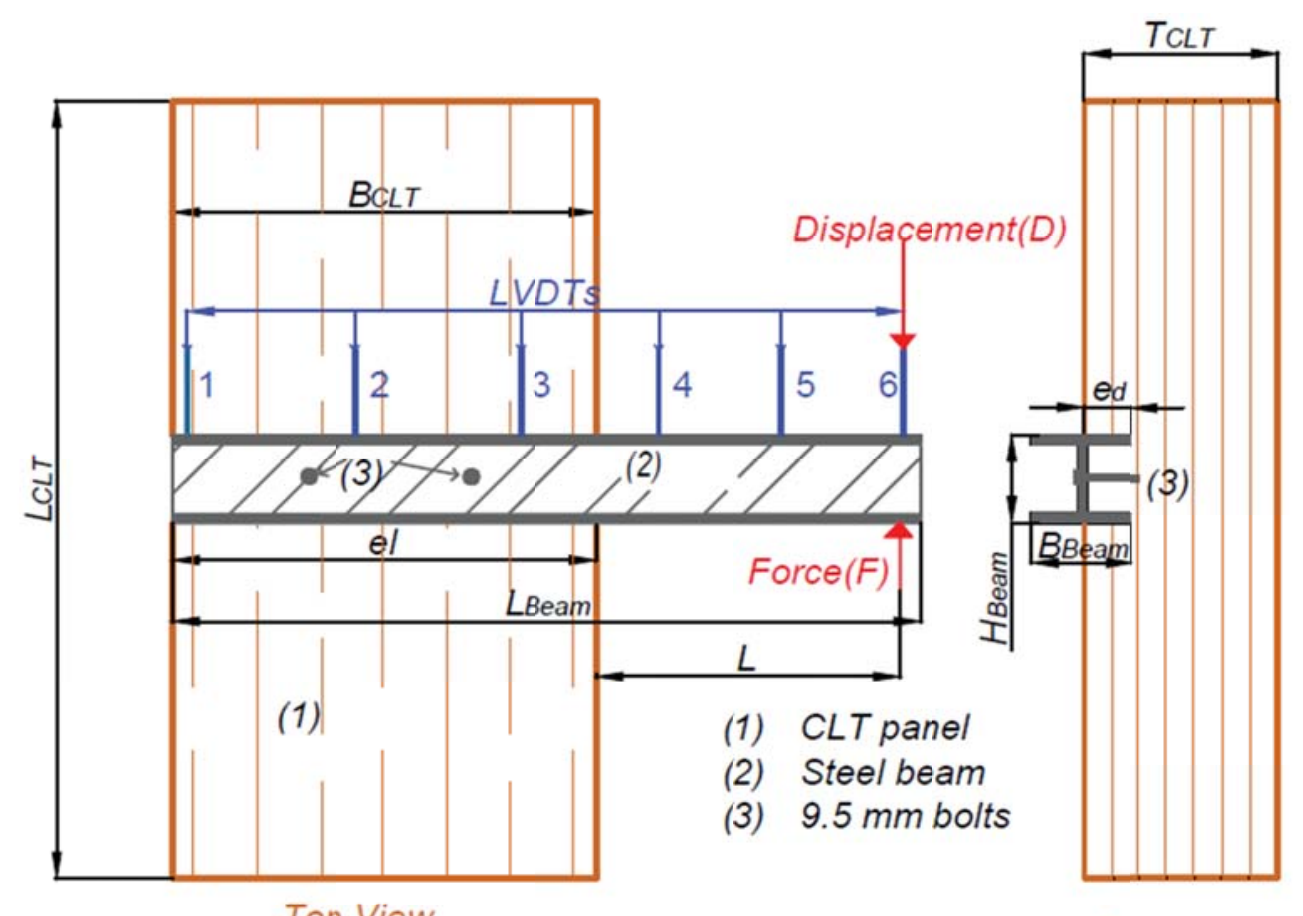

Top View

Side View

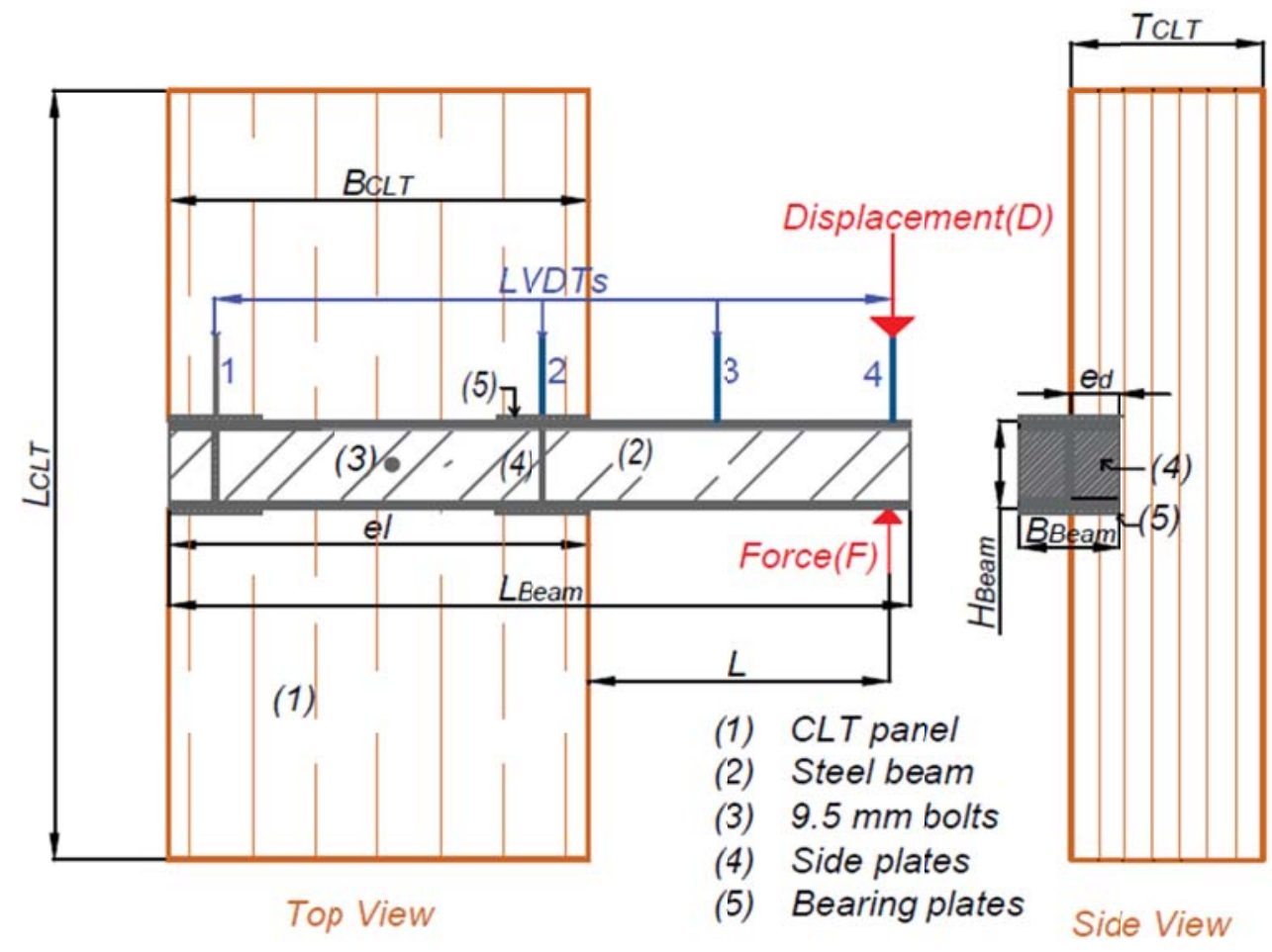


Figure 3

a)

c)
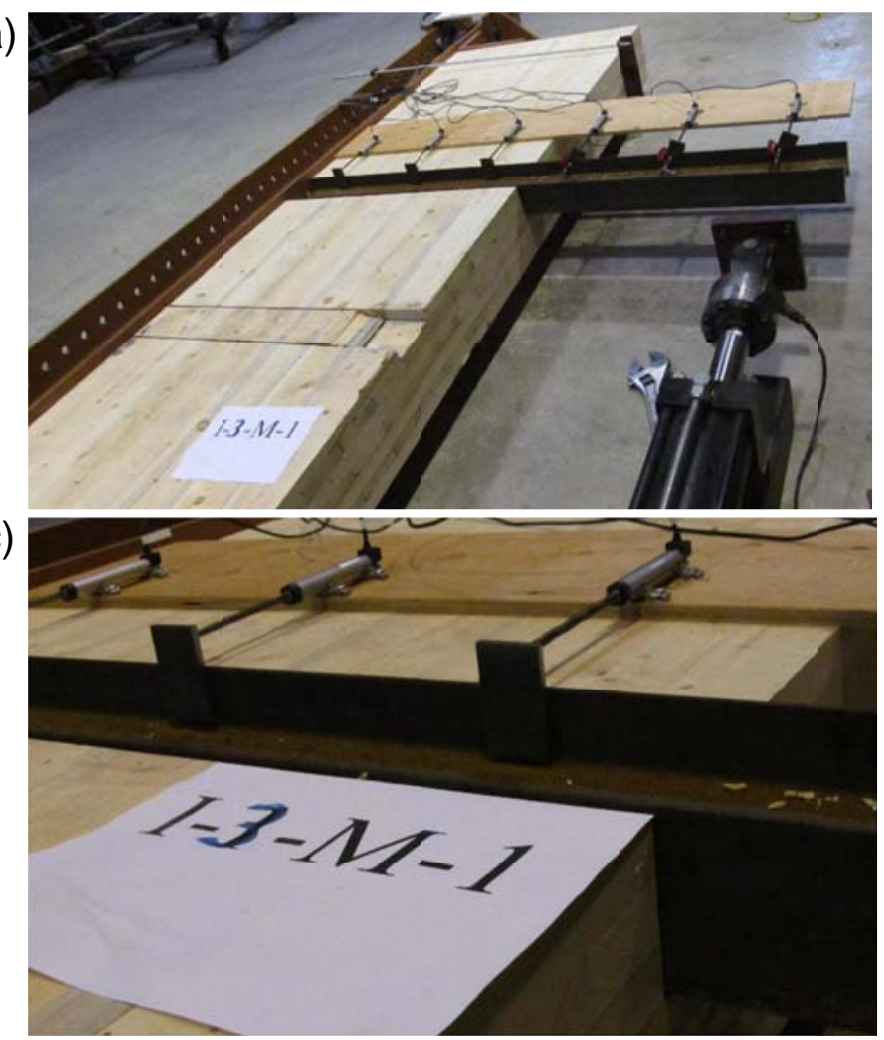

e)

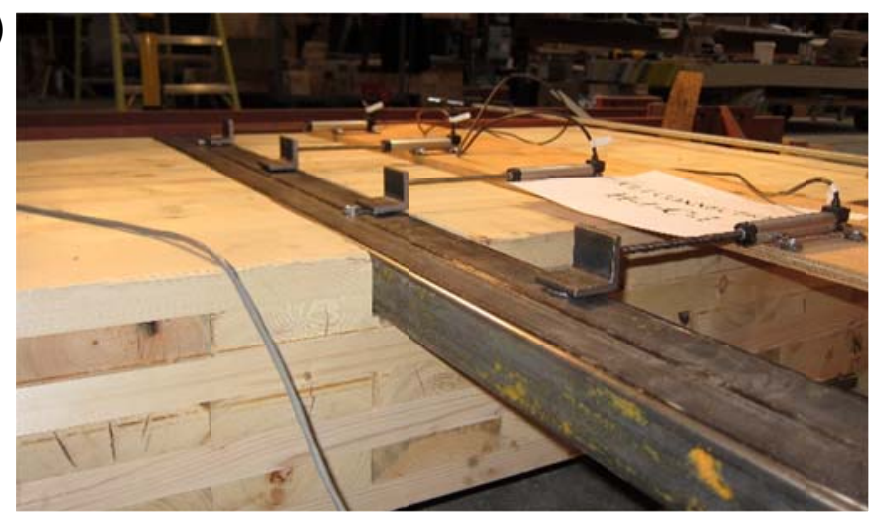

g)

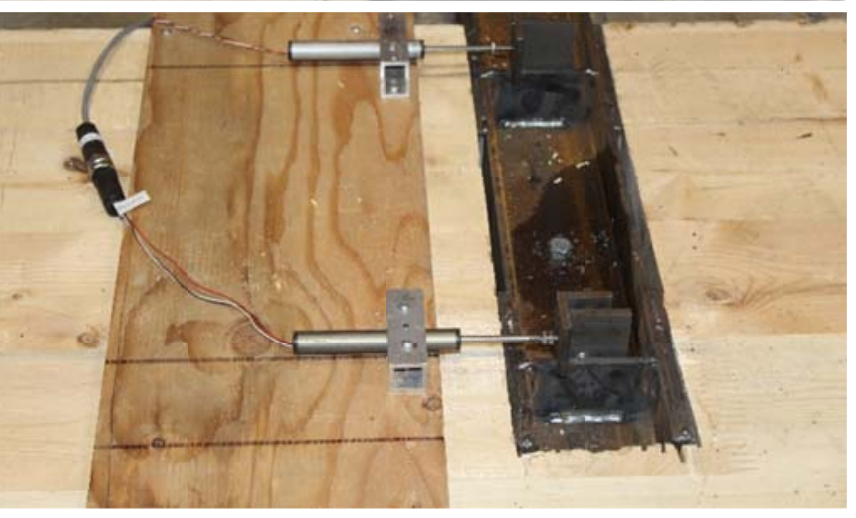

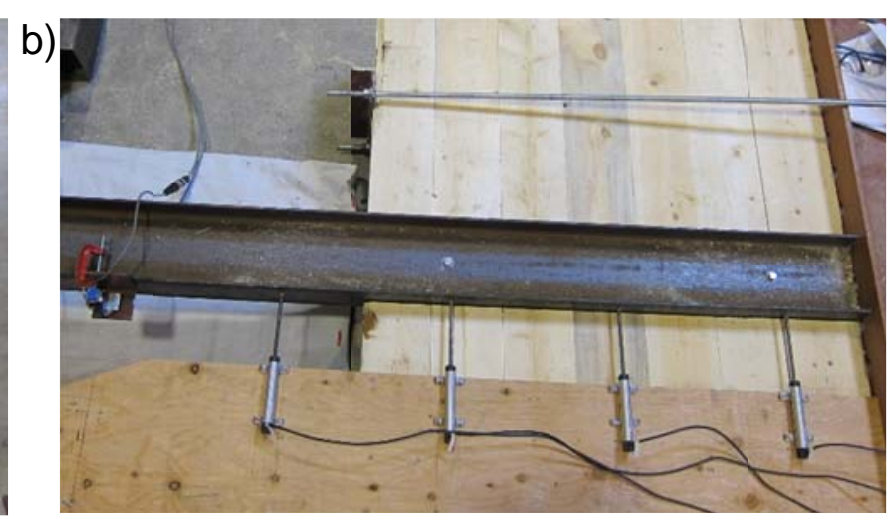
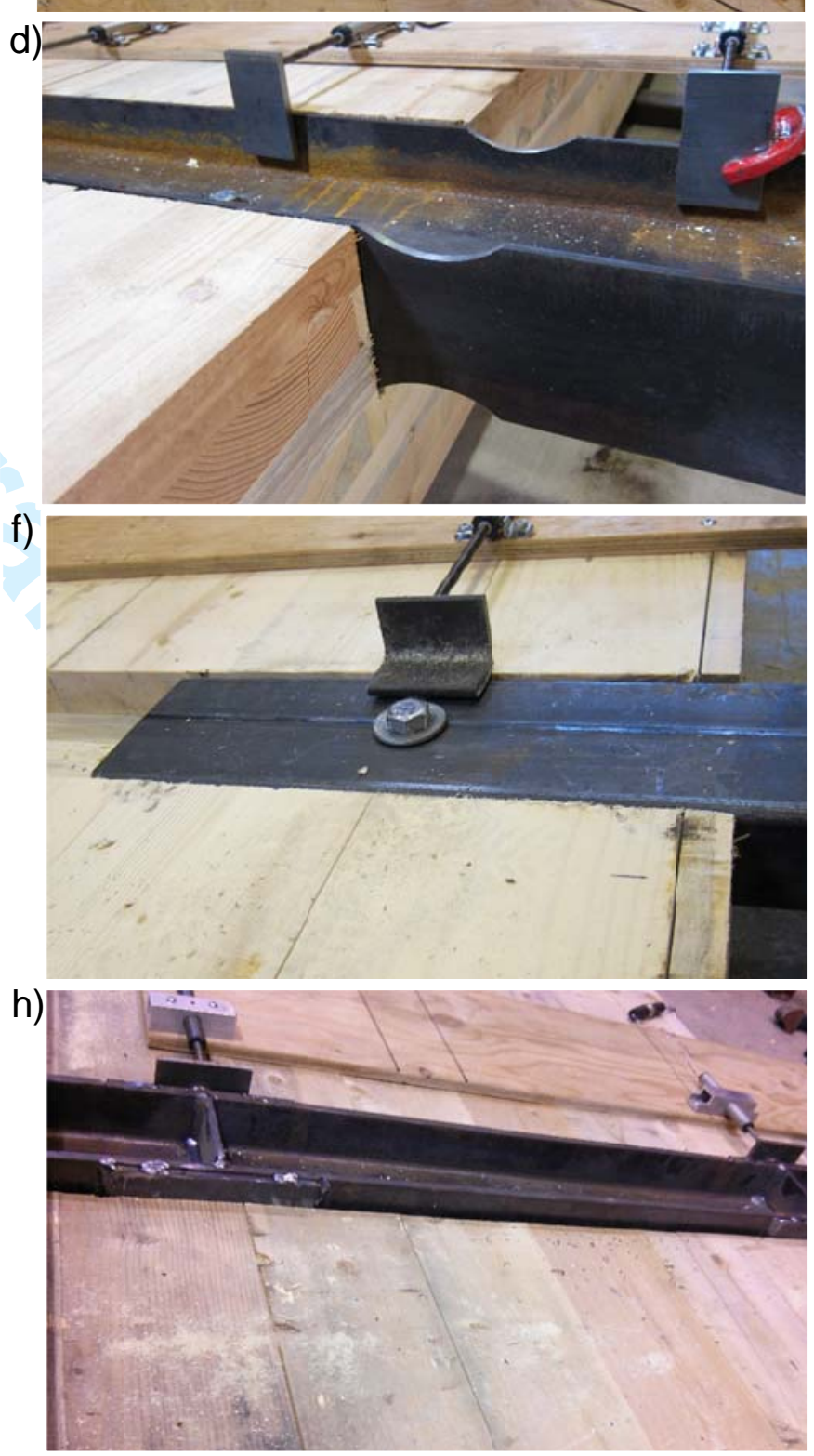
Figure 4

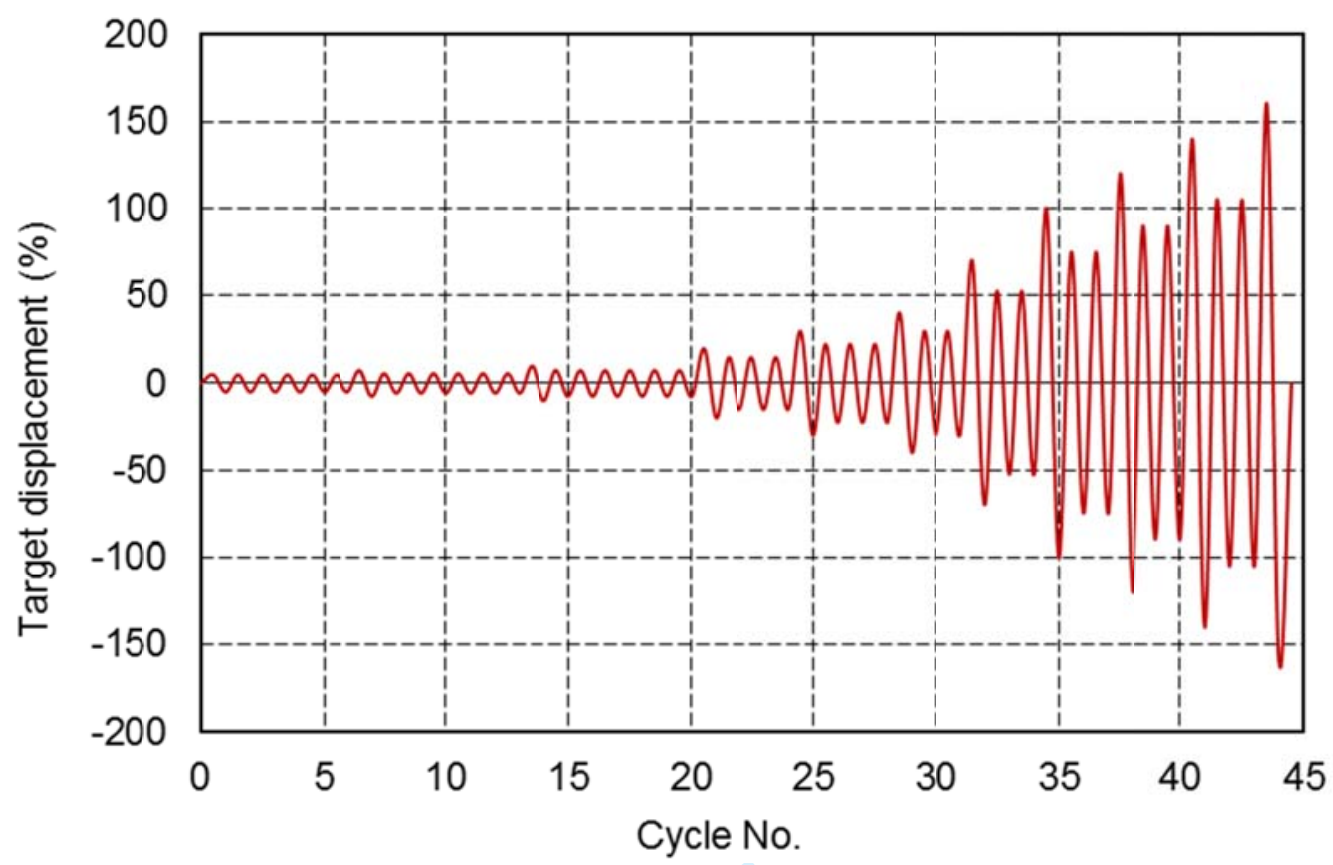

https://mc06.manuscriptcentral.com/cjce-pubs 
Figure 5

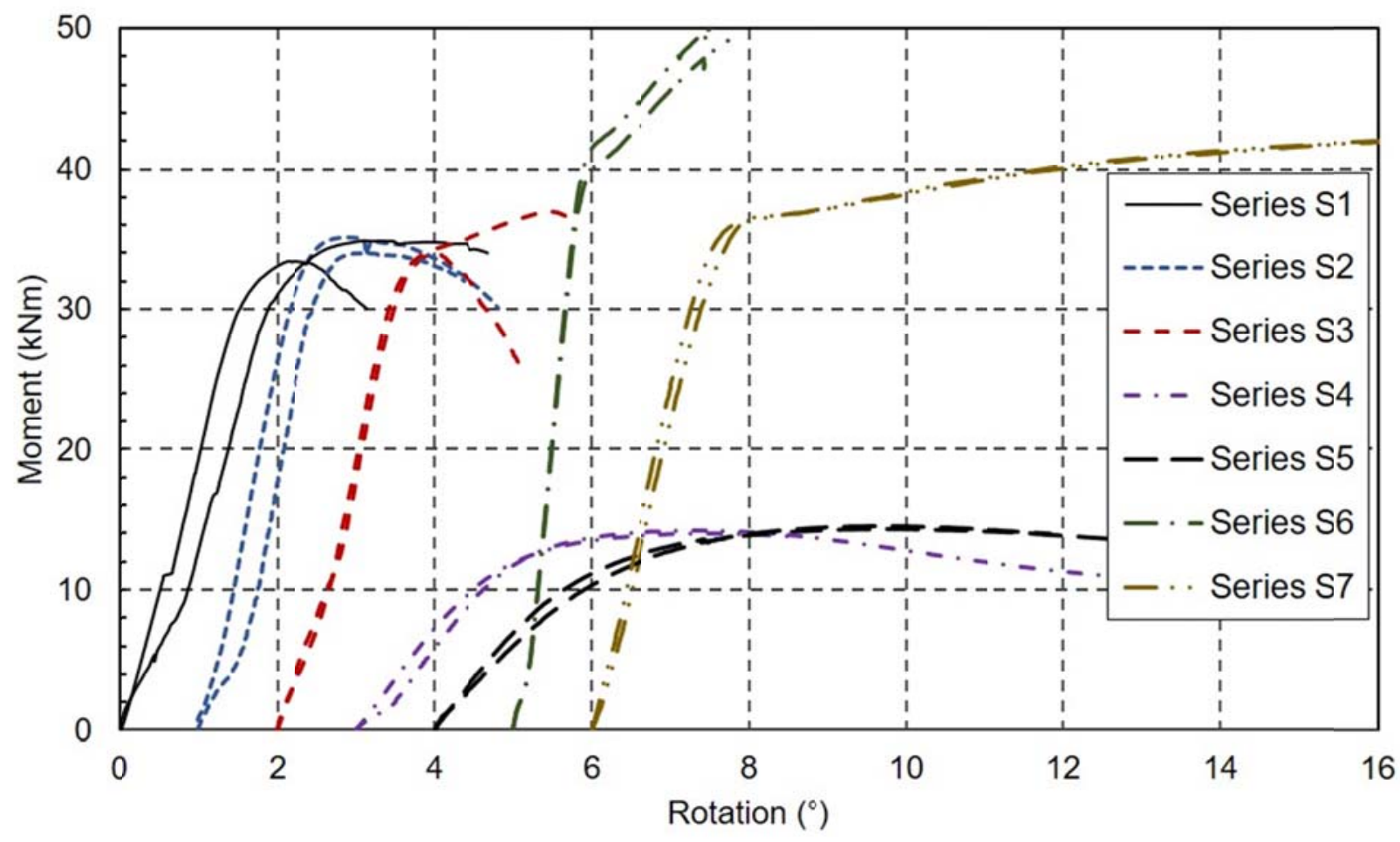


Figure 6

a)

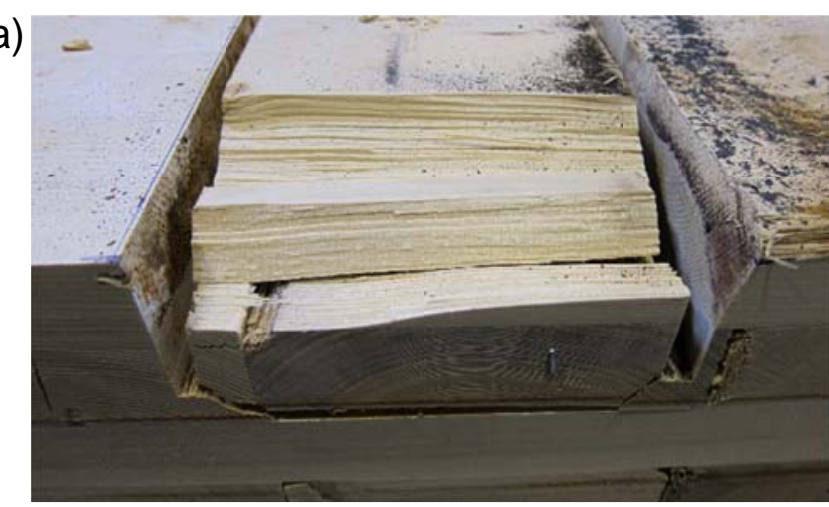

c)

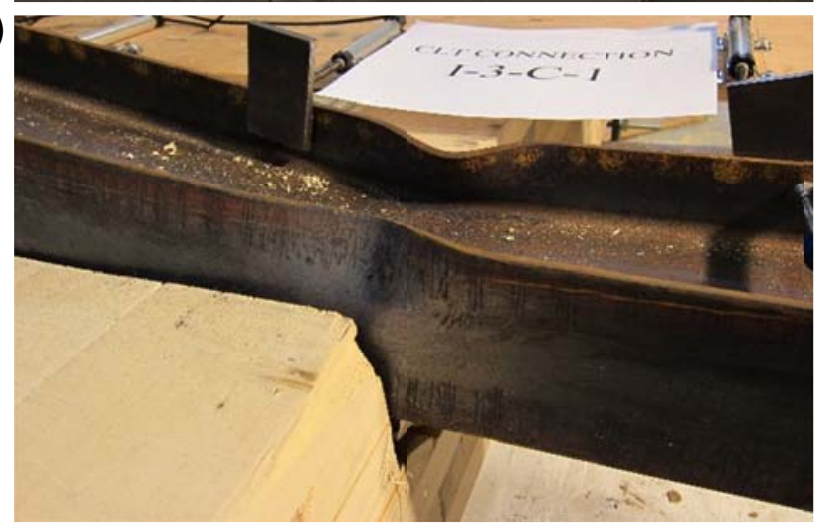

e)

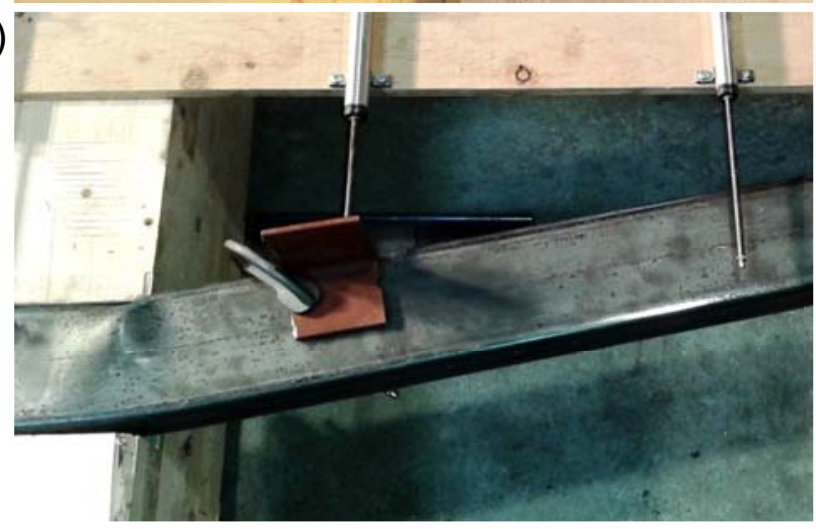

g)

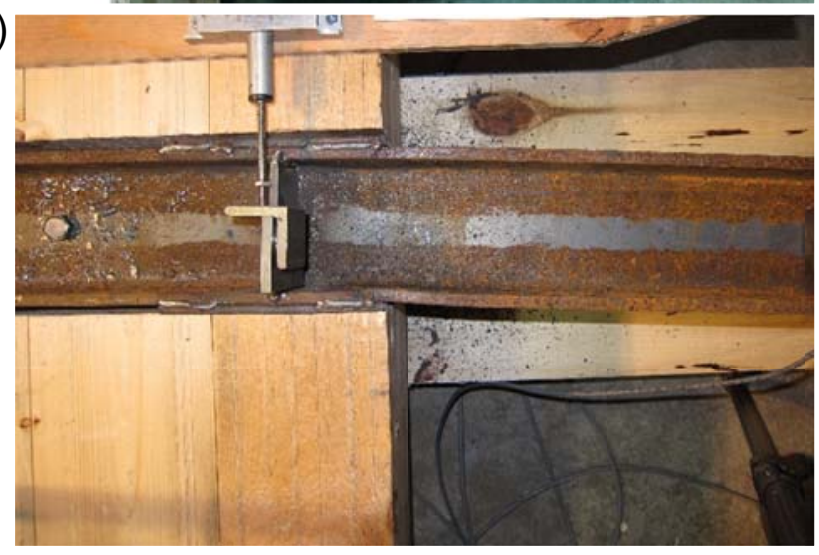

b)

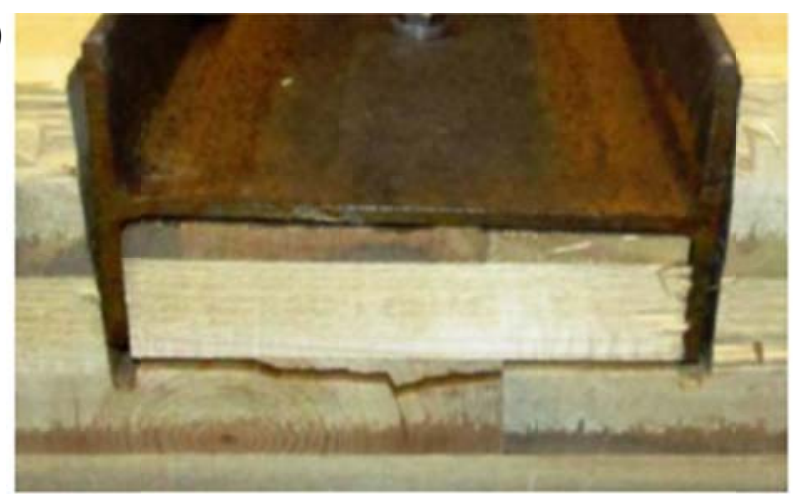

d)

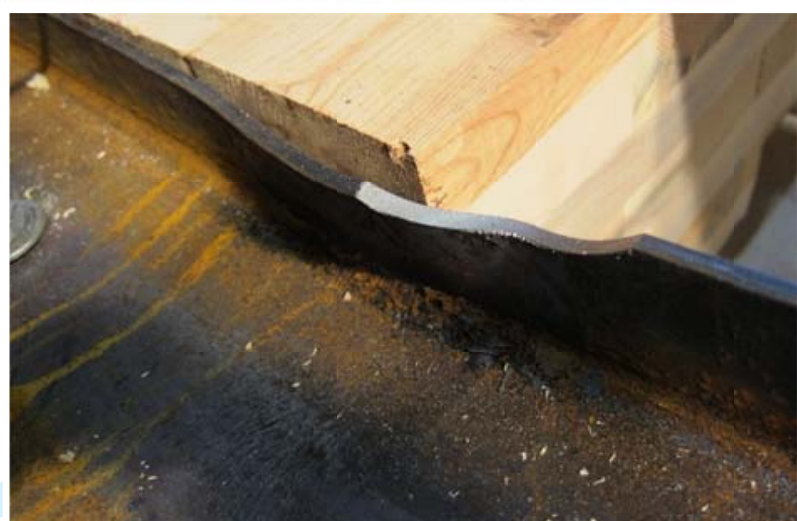

f)

h)
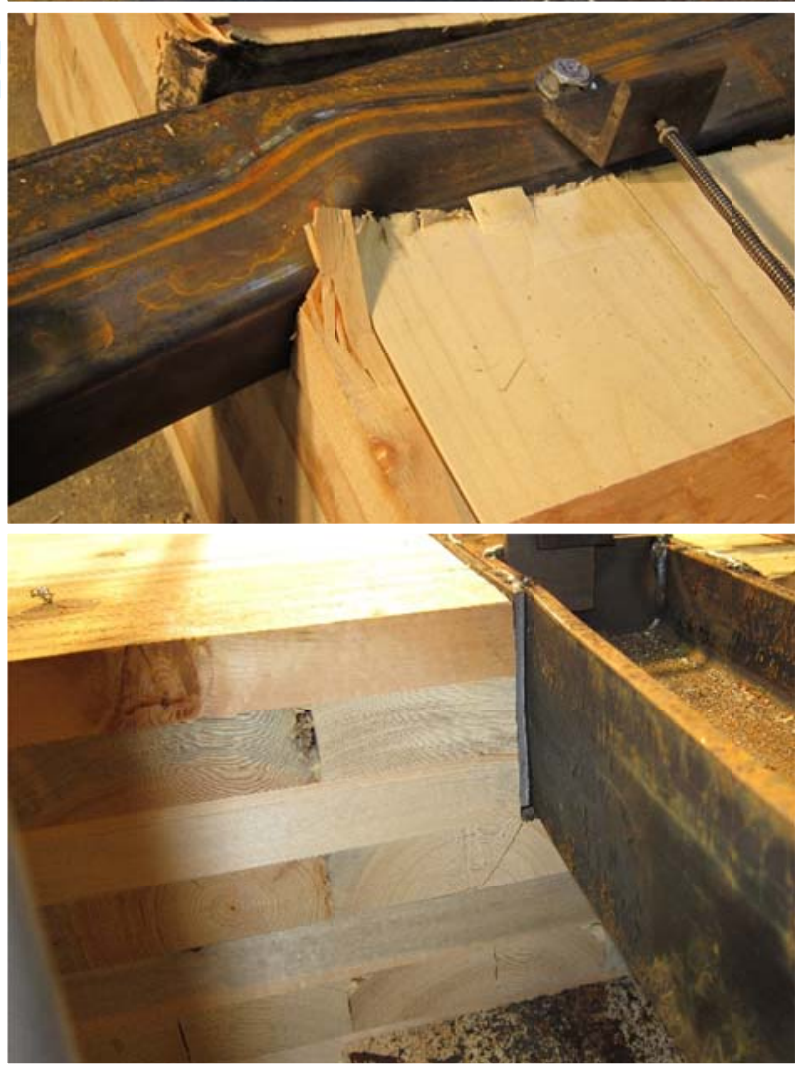
Figure 7
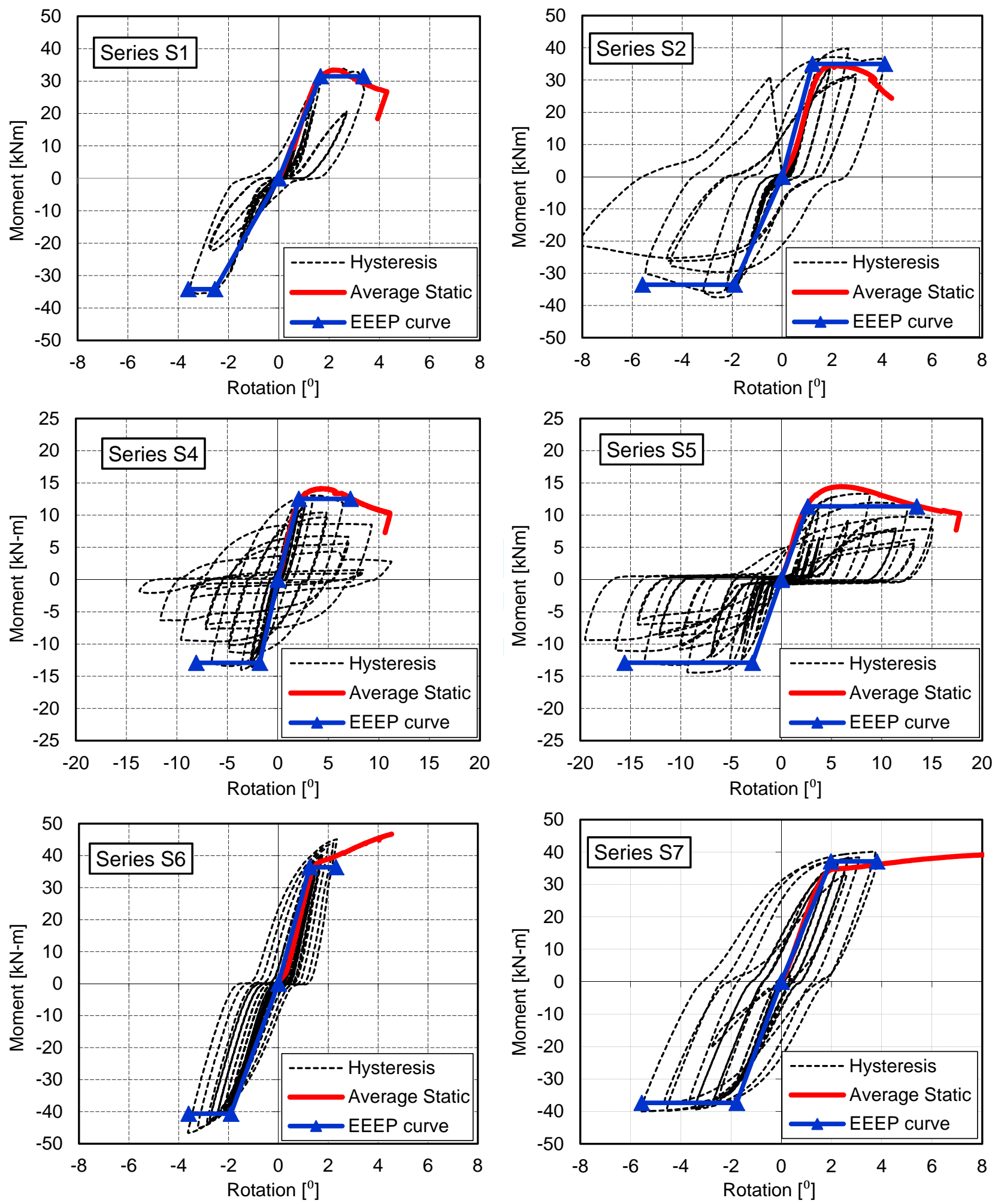
Figure 8

a)

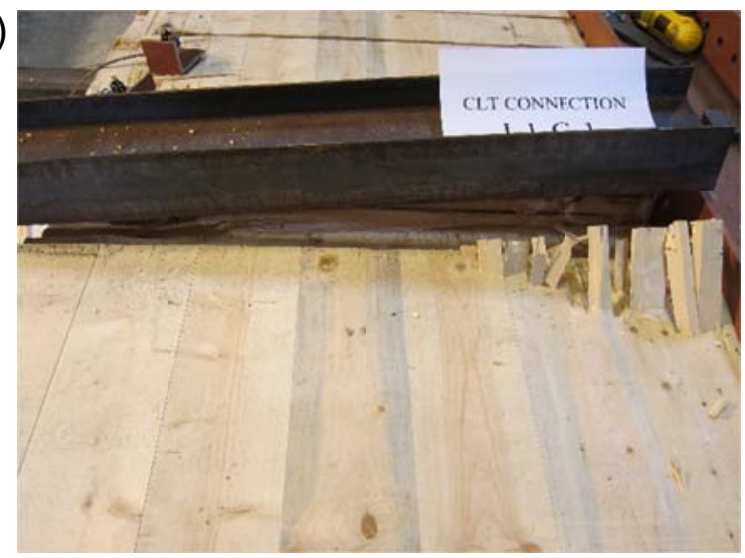

c)

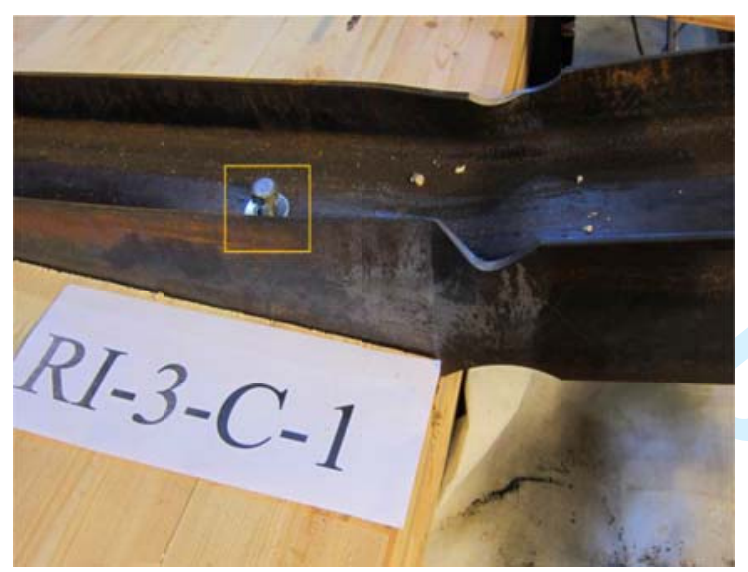

e)

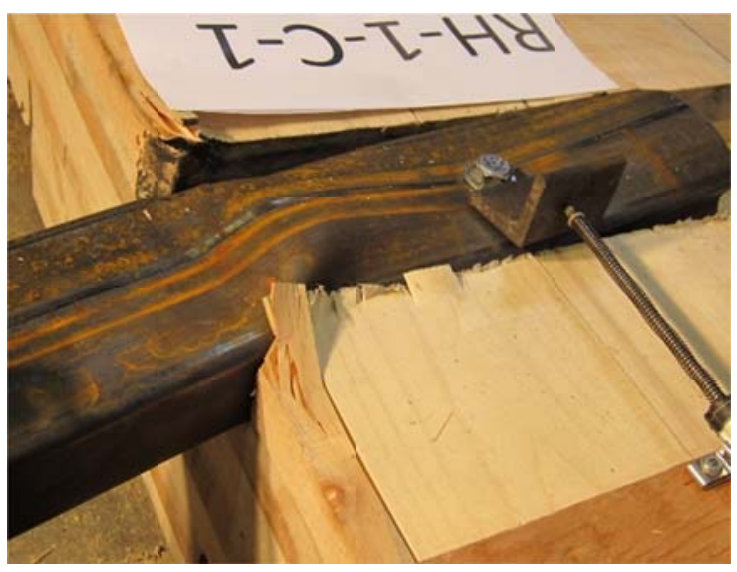

b)

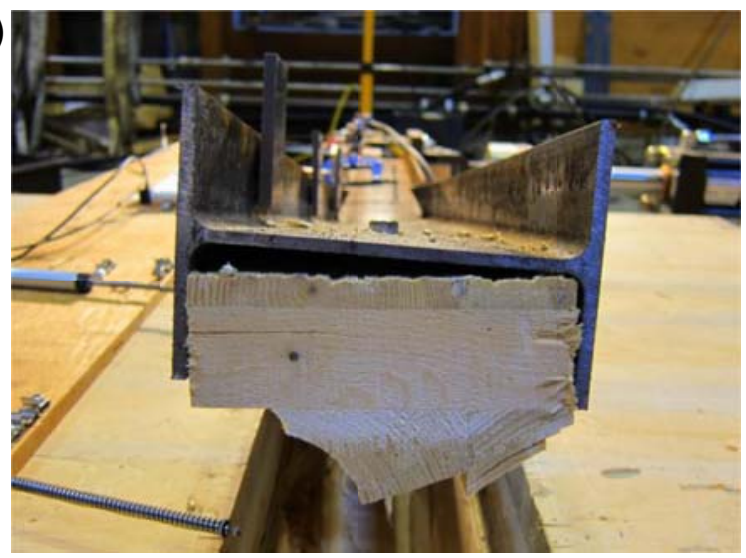

d)

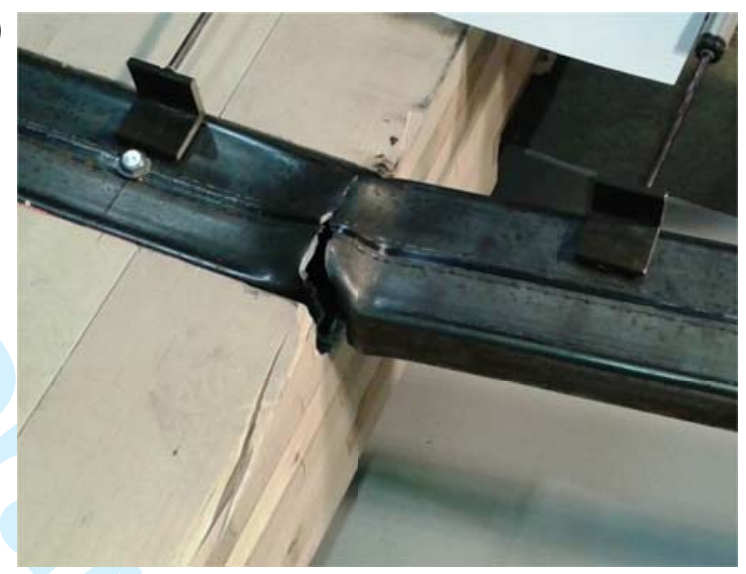

f)

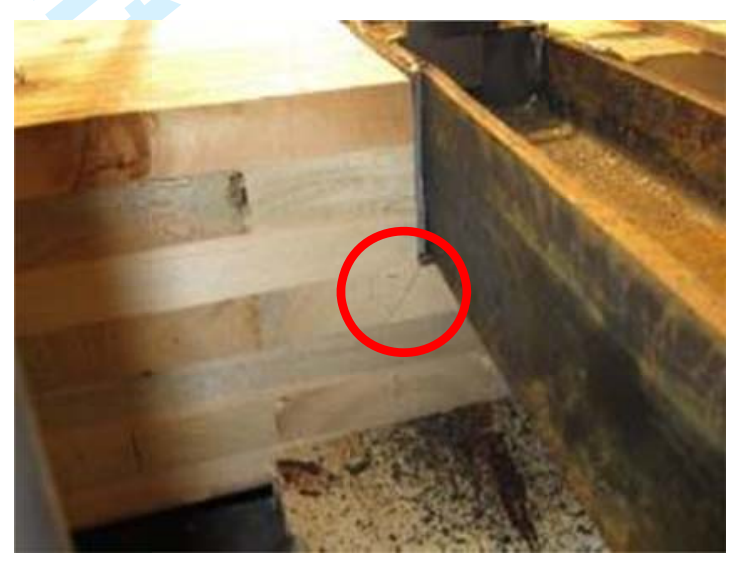

